\title{
DESLINDES DE LA MISCELÁNEA EN EL RENACIMIENTO ESPAÑOL
}

\author{
RAFAEl MALPARTIDA TIRADO \\ Universidad de Málaga \\ rmal@uma.es
}

\section{RESUMEN}

El objeto de este trabajo consiste en reflexionar sobre la idoneidad y el rendimiento descriptivo del término miscelánea para designar a determinadas obras, así como en esbozar una serie de convergencias y divergencias entre formas textuales que de un modo u otro se emparentan con el corpus de las misceláneas, y, en última instancia, del cotejo de esta práctica literaria con otras afines -incluidas las manifestaciones actuales-, inferir que su lugar en la historia literaria es más importante, desde un punto de vista no sólo sociocultural, sino también estético, de lo que suele pensarse.

Palabras Clave: Miscelánea; poliantea; Plinio el Viejo; Aulo Gelio; Pedro Mejía; Juan de Mal Lara; Antonio de Torquemada; Juan de Pineda.

\section{ABSTRACT}

The objective of this work consists on meditating about the utility of the miscellany term to denominate to certain works, and in sketching a series of convergences and divergences among textual forms related with the miscellany. Finally, by means of a comparison of these works with other texts tune-included the current manifestations-, we will be able to settle down that its place in the literary history is more important, from a point of view not only sociocultural, but also aesthetic, of what usually thinks.

KeY wORDs: Miscellany; polyanthea; Plinius the Old; Aulus Gelius; Pedro Mejía; Juan de Mal Lara; Antonio de Torquemada; Juan de Pineda. 
Si nos paramos a contemplar el estado de la cuestión sobre lo que ha venido a llamarse miscelánea, no ya en su lata acepción de 'mezcla, unión de unas cosas con otras', que extiende nuestro $D R A E$ a 'obra o escrito en que se tratan muchas materias inconexas y mezcladas', sino como un género literario de antiguo cultivo pero denominación y definición modernas, llaman la atención de entrada estos tres aspectos:

a) A la multiformidad designativa de este tipo de obras por parte de sus propios artífices, ha acompañado un desconcierto terminológico en su recepción, ya sea entre los lectores contemporáneos o entre los críticos modernos, y en el caso de estos últimos, el desconcierto se ha trasladado también al orden metodológico ${ }^{1}$.

b) Parece que el destino menor al que estaban abocados estos textos desde su génesis compositiva, se ha prolongado en el tiempo y ha provocado su casi exclusivo empleo subsidiario en la investigación literaria, especialmente en la anotación de textos áureos.

c) Como consecuencia de dicha función auxiliar, su estatuto genérico apenas si ha interesado, a lo cual hemos de añadir que, en la consideración particular de las distintas obras misceláneas, han abundado los términos peyorativos ${ }^{2}$.

El panorama no se presenta, sin embargo, tan desolador, puesto que ya contamos con alguna edición valiosa de estos textos ${ }^{3}$, del mismo modo que, en lo que atañe a su exégesis, se han producido acercamientos sólidos a su caracterización como género ${ }^{4}$, algunos de ellos incluso con ánimo reivindicativo 5 .

Para iniciar nuestro recorrido, es necesario tener en cuenta que el inaugurador del género en nuestras letras, Pedro Mejía, aun exhibiendo dicha condición fundacional, no deja

\footnotetext{
${ }^{1}$ La confusión puede rastrearse, por ejemplo, en las entradas de algunos diccionarios, donde se asocia un heterogéneo conjunto de obras como las Novelas ejemplares de Cervantes, El patrañuelo de Timoneda y los Diálogos de apacible entretenimiento de Lucas Hidalgo con la Varia historia de Zapata y la Silva de varia lección de Mejía (BLEIBERG y MARÍAS [dirs.], 1964, s. v. miscelánea, texto a cargo del propio Bleiberg), pero en la entrada correspondiente a Pedro Mejía, redactada por Alonso Zamora, sólo se alude al vocablo colección para definir la obra; incluso se llega en otro diccionario a mencionar el Libro de buen amor del Arcipreste de Hita porque «comprende episodios narrativos, expositivos, líricos y trata asuntos heterogéneos» (BUSTOS [coord.], 1985, s. v. miscelánea).

2 «Olla podrida» llegó a denominar Marcel Bataillon a la Silva de varia lección, cuyo autor no cumplía, en su particular escala de valores, la condición de «erasmista» (1966: 637); y el Jardín de flores curiosas de Torquemada, condenado en el célebre escrutinio del Quijote, es juzgado por Alfonso Reyes -que no entendió la poética compositiva del género- como un libro «fatigoso y ramplón», donde su autor «lo traga todo, y todo en desorden [...], introduciendo los temas sin razón ni cuento en una imposible mescolanza» (1948: 24-26); más recientemente Mercedes Alcalá Galán postuló la inserción de las misceláneas en un panorama literario tendente a la frivolidad y a la superficialidad durante la segunda mitad del siglo XVI («Las misceláneas españolas del siglo XVI y su entorno cultural», en Dicenda, 14, 1996, pp. 11-19).

${ }^{3}$ La más reciente corresponde al texto fundacional en lengua castellana, la Silva de varia lección de Pedro Mejía, a cargo de Isaías Lerner (Madrid, Castalia, NBEC, 2003), que viene así a culminar su intensa y extensa labor exegética sobre el libro del sevillano.

${ }^{4}$ Los puntales decisivos en la consideración de un género misceláneo han sido los trabajos de Asunción Rallo Gruss (1984: 159-180) y Antonio Prieto (1986: 219-263).

${ }^{5}$ Me refiero a artículos como uno singular de Francisco Márquez Villanueva sobre la no menos singular Miscelánea o Varia historia de Luis Zapata, donde toma como punto de partida la injusta desatención hacia el género («Don Luis Zapata o el sentido de una fuente cervantina», Revista de estudios extremeños, XXII/3, 1966, pp. 487-541, incorporado posteriormente a Fuentes literarias cervantinas, Madrid, Gredos, 1973, pp. 109-182).
} 
de mencionar en los preliminares de su Silva de varia lección una serie de precedentes en su dilecta literatura grecolatina. Es preciso, pues, acercarnos a esta añeja escritura -punto de referencia genérico y venero del sevillano- en busca de rasgos clarificadores. En el viaje hay que llevar varias cautelas antes de establecer parangones, para evitar precipitados anacronismos.

En primer lugar, es necesario distinguir entre ciencia embrionaria o deficiente y lo que hoy día entendemos por divulgación científica. Si los avances en la ciencia experimental han puesto al descubierto los errores de uno de nuestros antepasados, pero había en él un ánimo científico, nos estamos alejando de la pista de la miscelánea, pues esta se dirige no a una comunidad científica, sino a un público no especializado, igual que determinamos la frontera decisiva entre el tratado y el ensayo moderno.

Por impreciso que resulte el sintagma «ánimo científico», en especial tratándose de época tan antigua, es evidente que en el Aristóteles de los tratados zoológicos existe esa voluntad, en tanto que en el Claudio Eliano de la Historia de los animales, intención, destinatarios y materiales son de muy otro tenor, acumulando así este último una serie de encantadores disparates de orden zoológico en mayor medida que el estagirita. La escritura de Eliano se presenta, entonces, dentro del ámbito de «una literatura paradoxográfica ${ }^{6}$, en tanto que en el legado aristotélico hay obras esotéricas, según la conocida distinción que las separa de las exotéricas. Aristóteles llegó a confiar decididamente en el método experimental, practicando vivisecciones, conviviendo in situ con el objeto de estudio. Como explica Benjamin Farrington, tras una primera adhesión a las doctrinas de su maestro, Aristóteles «se sintió seguramente atraído por la idea de adquirir el saber solamente con los recursos del alma, sin la ayuda de los sentidos del cuerpo», pero -mediando en su trayectoria la presencia crucial de Eudoxo de Cnido- en los últimos doce años de su vida se consagró a «una completa restauración de los métodos de indagación científica que habían alcanzado su máximo con los jonios de la escuela hipocrática» (FARRINGTON, 1992: 116, 117). Eliano, por el contrario, confió demasiado en fuentes de segunda mano, elaborando su obra más con retazos librescos que con observación directa.

Existe, así pues, la fractura entre ambos modos de obrar, y era ya operante en estos primeros balbuceos de la ciencia. Eliano es autor también de una Varia historia, que probablemente sí nos pondría en la órbita de la miscelánea, pero la recurrencia a la Historia de los animales sólo nos interesa para ejemplificar esa división, ya que su monotematismo la aleja del género.

Fractura que nos pone en la pista de la nítida y trascendental separación de Pedro Mejía entre lengua culta y lengua vulgar, que funciona conjuntamente con la creación de un nuevo receptor no especializado que adviene con la consolidación de la Imprenta. Esta

\footnotetext{
${ }^{6}$ Así lo ha explicado José María Díaz-Regañón en su edición de la obra: «Casi todo es anecdótico en la obra de Eliano, pero en la época del escritor, la gente, ávida de evasión, admitía de buen grado todo lo que parecía adobado con anécdotas absurdas, maravillosas, exóticas, increíbles. Florece en esta época toda una literatura paradoxográfica que hace las delicias del público» («Introducción general» a ELIANO, 1984: 15). Téngase en cuenta la filiación con la literatura fantástica que se ha propuesto para textos como el Jardín de flores curiosas de Antonio de Torquemada, que figura, junto a la Silva de Pedro Mejía, en la Antología española de literatura fantástica preparada por Alejo Martínez Martín (Madrid, Valdemar, 1996, pp. 37-50). Antonio Prieto ha destacado este aspecto en «El contar fantástico en las misceláneas del siglo XVI» (Lucanor, XIV, 1997, pp. 47-59).
} 
diferencia de público lector por causa de la invención de los «moldes» no se establecía, por razones obvias, en la literatura griega y latina, de igual manera que semejanzas con la distinción entre lengua culta y vulgar sólo aparecen, y muy atenuadas en comparación con nuestro siglo XVI, a nivel dialectal-genérico en la literatura griega -esto es, a cada género correspondía aproximadamente el cauce dialectal en el que se gestó-, y a nivel puramente estilístico en la más homogénea lengua latina 7 . Pero sí podemos trazar una red de equivalencias para que funcione la separación entre público especializado y no especializado, tan importante para la consideración del género misceláneo. Por encima de cualquier peculiaridad histórica, en la creación textual existe una distinción, con sólo alterar un fonema, entre lo esotérico y lo exotérico, según la conocida división de las obras de Platón y Aristóteles -recuérdese lo que acabamos de indicar respecto a Eliano-, de modo que el primer tipo de escrito, dirigido al erudito o iniciado en una materia, equivale al tratado escrito en latín en la época de nuestra historia lingüística en la que convive y hasta colisiona con la lengua romance. El ínfimo nivel de alfabetismo y de acceso o atesoramiento particular de obras literarias en la época grecolatina, que cambia tímidamente pero en seguro crecimiento durante el período de gestación y desarrollo de las obras impresas, no impide que el escritor genere su obra para un público lector de diferentes competencias y que busca variados fines en la obra literaria ${ }^{8}$.

Otra precaución consiste en deslindar atentamente el estado de conservación y ordenación moderna de determinadas obras respecto a su génesis compositiva. Así, por ejemplo, las Moralia de Plutarco ofrecen apariencia miscelánea en su difusión más reciente sólo porque el material disperso del autor griego ha sido pertrechado unitariamente en torno a ese término matriz, y el resultado es de una evidente dispersión temática. Lo mismo sucedía con las traducciones de nuestro siglo XVI, por tomar como punto de referencia la época en la que surgen nuestras misceláneas en lengua vulgar ${ }^{9}$. Los avatares editoriales no deben confundirnos en este caso, porque de lo contrario podemos asociar a la miscelánea cualquier recopilación a posteriori de opúsculos concebidos independientemente ${ }^{10}$. En el caso de Plutarco, parece que las hoy denominadas Morales eran creación «paralela» y secundaria respecto a sus Vidas paralelas, proyecto de escritura que realmente le interesaba.

Realizados estos matices, podemos seguir avanzando con estas dos premisas: toda obra con intención científica y dirigida a un receptor especializado, está fuera del género misceláneo; toda serie de obras surgidas con carácter independiente, pero conservadas y reordenadas posteriormente, por más apariencia miscelánea que presenten al reinte-

${ }^{7}$ Cf. Ludwig Bieler, Historia de la literatura romana, Madrid, Gredos, 1992, pp.12-13; y José Alsina, Teoría literaria griega, Madrid, Gredos, 1991, pp. 54-77.

${ }^{8}$ Aun moviéndonos en terreno sinuoso que apenas si permite insatisfactorias conjeturas, $c f$. además del ya clásico Lectura y lectores en la España del siglo XVI y XVII de Maxime Chevalier (Madrid, Turner, 1976), los numerosos datos que nos brinda Ricardo García Cárcel sobre la producción literaria y su público lector en Las culturas del Siglo de Oro. II, Madrid, Historia 16, 1998, en especial pp. 152-167.

${ }^{9}$ Cf. Jorge Bergua Cavero, Estudios sobre la tradición de Plutarco en España (siglos XIII-XVII), Universidad de Zaragoza, 1995, pp. 161-188; y Alicia Morales Ortiz (2000), Plutarco en España. Traducciones de Moralia en el siglo XVI, Universidad de Murcia, 2000.

${ }^{10}$ Jean-Marc Mandosio sí asocia estos textos con el género misceláneo: «Plutarque lui-même avait écrit toute une série d'opuscules sur les sujets les plus divers, réunis par la suite sous le titre d'Oeuvres morales ou Oeuvres mêlées, qui seront considérés comme autant de chapitres disparates d'une vaste miscellanée» (2003: 12). 
grarse al conjunto, están igualmente excluidas del género. Tanto en uno como en otro caso, no existe una voluntad de amplia difusión divulgativa ni un principio de composición unitario, condiciones necesarias para que apliquemos el término miscelánea tal y como lo entendemos en este trabajo.

Así las cosas, podemos examinar una obra de vastas dimensiones y radio de acción mayor, la Historia Natural de Plinio el Viejo, que a falta de otro término más significativo, ha sido asociada casi siempre con el enciclopedismo, de igual modo que figura bajo el marbete de «tratados en prosa» o «literatura científica o técnica» en las historias literarias que eligen la clasificación genérica para su contenido. Como bien indica Jean-Marc Mandosio en su recorrido histórico por el género, la enciclopedia «est en quelque sorte le frère ennemi de la miscellanée, puisque l'absence de structure de la seconde constitue l'antithèse parfaite de la forte structuration de la première» (MANDOSIO, 2003: 7), pero tal vez tenemos esa percepción porque aplicamos al término enciclopedia los rasgos de su configuración moderna en el período ilustrado. Tal vez hay que contemplar la posibilidad de que haya características secundarias más relajadas en el género misceláneo, en este caso la voluntad de ordenación; de lo contrario, tampoco un texto como el Jardín de flores curiosas de Antonio de Torquemada pasaría por tamiz tan ceñido ${ }^{11}$.

Aunque sólo se ha conservado una parte de la magna obra de Plinio, sí tenemos la oportunidad de leer su declaración de intenciones respecto a la Historia Natural. Es difícil separar grano y paja en su prólogo, porque consideraciones probablemente valiosas conviven en apretado margen textual con prevenciones y tópicos de las dedicatorias. Plinio se dirige al emperador Tito, sucesor de Vespasiano, con la pose de las nugae y se defiende de posibles críticas de sus detractores, aplicando, como es habitual, el ungüento antes de la herida. Pero agitando el cedazo obtenemos una serie de comentarios suculentos para nuestro objeto de estudio.

Nótese cuán cerca de las palabras liminares de Mejía se hallan estas otras de Plinio al frente de su obra, que podemos agrupar del siguiente modo:

a) Consciencia de escritura novedosa, ya sea por su condición genérica o por sus dimensiones y objeto abarcado:

Determinado he, graciosísimo Emperador, ofrecerte por esta mi atrevida letra los libros de la Historia Natural, obra nueva a las Musas de tus romanos y postrero parto de mi ingenio (PLINIO, 1998: 14a) ${ }^{12}$.

Haze también dificultoso este mi intento [el] seguir camino no hollado de otros autores y por do el ánimo desconfíe de poder ir adelante, porque entre los latinos ninguno lo ha tentado, y entre los griegos, no se halla quien solo le haya tractado todo (PLINIO, 1998: 15b).

\footnotetext{
${ }^{11}$ Hemos de tener en cuenta que Mandosio, como algunos estudiosos de la miscelánea española, considera el desorden compositivo como la característica matriz del género. Sin embargo, el desorden puede verse incrementado por un anómalo proceso de redacción (Varia historia de Zapata), o puede recomponerlo el lector interesado en algún aspecto particular -y empleando la miscelánea como enciclopedia, por tanto- gracias a los epígrafes internos, tablas e índices.

${ }^{12}$ Dadas las dificultades de interpretación de este texto, que ha creado cierta confusión entre los investigadores, tengo en cuenta el texto latino incluido en la edición bilingüe francesa (Pline l'Ancien, Histoire Naturelle. I, París, Les Belles Lettres, 1950, pp. 47-57), así como la traducción al español de Antonio Fontán (Plinio el Viejo, Historia Natural. I, Madrid, Gredos, 1995, pp. 211-222).
} 
b) Obra en segundo grado, que compila textos pretéritos sin ocultar su aprovechamiento e identidad:

Verse ha ser esto ansí en no haver callado sus nombres, porque cierto es cosa benigna y llena de noble respecto confesar cada uno por quién ha aprovechado, no como hizieron muchos de los que he leído, los cuales, cotejándolos con los más antiguos, hallé haver trasladado a la letra de sus escriptos, sin discrepar en un punto de todo cuanto dixeron, no haziendo dellos mención, no contendiendo con aquella virtud vergiliana o con la sinceridad de Cicerón (PLINIO, 1998: 16b).

c) Exhibición del desvelo lector que permite llegar a esas fuentes:

Veinte mil cosas dignas de cuidado (porque, como dize Domicio Pisón, no son otra cosa los libros sino tesoros), con lección de casi dos mil volúmines, de los cuales, muy pocos rebuelven los estudiosos por el secreto de la materia, encerramos en nuestros treinta y seis, sacado de ciento los más principales, añadiendo no poco que no supieron nuestros antecesores o que después ha hallado la vida. No dubdo sino que se me havrán pasado muchas cosas, pues soy hombre y ocupado en oficios públicos y escrivo en horas hurtadas a los negocios. Pero porque no pienses que he perdido el tiempo, te hago saber que los días gasto en tu servicio y de las noches duermo sólo aquello que basta para vivir, contentándome solamente con que mientras escribo estas nonadas (como dize Marco Varrón) vivo más horas, porque a la verdad no es la vida sino vela (PLINIO, 1998: 15b).

Esta otra declaración, que podría venirnos de perlas para establecer afinidades con la búsqueda de un lector no erudito en la miscelánea renacentista en lengua vulgar, burla el cedazo y hemos de desecharla:

[...] ¿para qué lees esas cosas, oh Emperador? Para el baxo vulgo se escribieron y para la caterva de los labradores y oficiales y, finalmente, para gente no estudiosa. ¿Para qué te hazes juez? Cuando esto escrivía no te contava en el número de los que habían de juzgarme; no creí de tu grandeza que se havía de humanar tanto (PLINIO, 1998: 14b).

De hecho, el horizonte de difusión de la Historia Natural, a la luz de estas palabras, ha sido tasado de modo bien distinto, incluso antagónico, por parte de la crítica. Sólo unos ejemplos: René Martin y Jacques Gaillard destacan que Plinio «se considérait comme investi d'une veritable mission sociale: dans sa préface, il déclare en effect, no sans solennité, qu'il écrit 'pour le peuple, pour les paysans et les artisans, pour ceux en un mot qui n'ont pas fait d'études'; il y a chez lui une réelle volonté de démocratiser le savoir et un souci profond de se rendre utile aux humbles et aux pauvres» (1995: 181), en tanto que Michael von Albrecht, en términos más generales, opina que «l'opera di Plinio non è uno scritto didattico; oggi lo si assegnerebbe al genere enciclopedico, che si rivolge al lettore colto» (1994: 1266). Una solución de consenso es la de Joan Gómez Pallarès, para quien, «a pesar de su vasta erudición, el carácter de la obra pliniana no es selectivo en cuanto a lectores se refiere. Plinio no se dirige en concreto a los especialistas, sino que intenta construir una enciclopedia útil a la mayor parte de público posible. Su objetivo último es la difusión de una cultura general, en este caso, relacionada con las ciencias de la naturaleza, y entre un público diríamos ni muy instruido ni muy iletrado» (2003: 142). 
En esta consideración, además de que se advierte un lugar común de las dedicatorias (carácter ínfimo de la obra vs. dignidad del dedicatario), interfiere un problema antes apuntado: ¿escribe Plinio para una comunidad científica? Conservamos la imagen idealizada, que transmitió su sobrino por vía epistolar, de un Plinio no sólo infatigable lector, sino también dado a la experimentación y a la observación, hasta el extremo de que la leyenda culmina con su muerte durante la investigación del Vesubio, cuya fiereza -según el joven de los Plinios- acabó con él ${ }^{13}$. Probablemente se confunde aquí un espíritu inquieto, emprendedor, con lo que antes denominábamos «voluntad científica» a propósito de Aristóteles. Además, parece que se refiere más al asunto humilis que al receptor, de igual modo que por vía poética Virgilio no podía pretender dirigirse al campesino iletrado, pero sí cantar al cultivo de las tierras según los deseos de Augusto.

Lo que nos interesa del último pasaje recordado para nuestro propósito es que Plinio menciona, junto al proyecto de la Historia Natural, otro que mueve al escritor hacia designios más altos en la creación literaria: dejar memoria histórica de la clase de los mandatarios y guerreros, escritura de Plinio hoy perdida: «Ya yo he, en un volumen de bastante grandeza, tractado de tu valor y del de tu padre y hermano, comenzando la historia de nuestros tiempos desde el fin de la de Aufidio Basso» (PLINIO, 1998: 16a). Aquí sí que advertimos la afinidad con el Mejía que se consagra a la historiografía y da cuenta de las hazañas y programa de gobierno de Carlos $\mathrm{V}^{14}$, igual que pensamos en el Zapata que se lamenta de la pobre acogida de su Carlo famoso; ambos escriben sus misceláneas siempre como proyecto paralelo de segundo orden o complementario respecto al que hoy consideraríamos panegírico. Esta última labor está más relacionada con su profesión y aspiraciones, es una prolongación natural de sus vidas en la escritura, si pensamos no en los escritores nocturnos, sino en el Plinio soldado, el Mejía cronista y el Zapata cortesano.

Plinio escribe en una coyuntura propicia a la compilación, tras los intentos parciales de los que le precedieron, igual que Mejía ofrece una summa del saber que hay en su biblioteca, vedada a la mayoría. Si tanto el término miscelánea como el de enciclopedia resultan anacrónicos, y se aplican de manera retroactiva a obras como la de Plinio, parece evidente que, atendiendo a sus propias declaraciones, recoge más rasgos de lo que hoy entendemos por miscelánea (escritura en segundo grado, proyecto individual y propósito no científico) que de la enciclopedia (aspiración global y no particular, proyecto necesariamente colectivo y ordenación sistemática), máxime porque este último término

${ }^{13} \mathrm{Cf}$. las dos cartas de Cayo Plinio Cecilio que con buen criterio se han incluido al frente de la ya citada traducción de Francisco Hernández (pp. 11-14). Las controvertidas circunstancias de su muerte llegan a ofuscar a Guy Servat, introductor de la antes mencionada traducción moderna al español. $C f$. su «Diagnóstico de un deceso» « ¿Por qué esta deformación de la historia?» (pp. 31-35).

${ }^{14}$ En el caso concreto de Mejía, sobre este aspecto imprescindible para la comprensión de su escritura, $c f$. Asunción Rallo Gruss, «El sevillano Pedro Mexía, historiador de Carlos V», Actas del I Congreso de Historia de Andalucía. II, Córdoba, Publicaciones del Monte de Piedad y Caja de Ahorros de Córdoba, 1978, pp. 307-314; J. Sepúlveda Fernández, «Letteratura e potere nella Silva de varia lección di Pero Mexía: 1'immagine di Carlo V», Atti del Convegno Cultura e Potere nel Rinascimento, Milán, Società di Studi Francesco Petrarca, 1997, pp. 347-355; y Dominique de Courcelles, «Le livre médiateur des instances politiques et culturelles: étude des deux textes préliminaires de la Silva de varia lección de Pedro Mexía, sévillan (1540)», Actes du «Colloque Relations entre identités culturelles», París, Presses de la Sorbonne Nouvelle, 1998, pp. 189-200. 
está más marcado por su uso en un período muy determinado de la historia de la cultura, lo que limita su recurrencia ${ }^{15}$.

Si seguimos teniendo dudas, y hemos de acudir a matices de mixtura con esta obra, en el caso de Aulo Gelio, otro amigo de la nocturnidad lectora, como Plinio y Mejía, y ya desde el título de la obra, caben menos dudas, y de hecho lo cita el sevillano como uno de sus modelos genéricos.

Llama la atención el rosario de vocablos que aporta Aulo Gelio para poner en antecedentes a su lector sobre títulos que «plerique alii utriusque linguae scriptores in id genus libris fecerunt» (GELIO, 1967: 2) ) $^{16}$, la mayoría de los cuales hoy no se conservan, relación en la que destacan los términos que aluden a la compilación ${ }^{17}$. Según la útil clasificación de Mandosio, que se propone «reconstituer le champ sémantique du genre auquel appartiennent les Nuits attiques», apreciamos cuatro categorías:

les titres qui insistent sur la variété du contenu et sur son agrément (Silves, Prairies, Pré, Florilège, Péplum, Tapisseries...); ceux qui insistent sur sa richesse (la Corne d'Amalthée, les Rayons de miel, le Verger -qui fournit des fruits); ceux qui font allusion aux travaux de l'auteur (Lampes, Nuits, Lectures, Trouvailles...); enfin, plus prosaïquement, ceux qui spécifient le contenu des ouvrages (Lectures, Problèmes, Conjectures, Histoires, Leçons, Lieux communs, Épîtres, Questions) (MANDOSIO, 2003: 11).

Nociones todas apuntadas, en cierto modo, por Mejía desde el título de Silva de varia lección y su glosa preliminar en el «Prólogo» y el «Prohemio y prefación de la obra». Ahora bien, lo que nos interesa no es tanto el nombre que le ponemos a la criatura como el efecto de esa compilación afanosa: el atajo que se crea con la nueva obra. Cuando Aulo Gelio se pinta a sí mismo

Ego uero [...] ipse quidem uoluendis transeundisque multis admodum uoluminibus per omnia semper negotiourum interualla in quibus furari otium potui exercitus deffesusque sum, sed modica ex his eaque sola accepi quae aut ingenia prompta expeditaque ad honestae eruditionis cupidinem utiliumque artium contemplationem celeri facilique compendio ducerent aut homines aliis iam uitae negotiis occupatos a turpi certe agrestique rerum atque uerborum imperitia uindicarent (GELIO, 1967: 3-4),

${ }^{15} C f$. el artículo dedicado por Diderot y D'Alembert al término enciclopedia (hay traducción española, a cargo de Jesús Torbado, en La Enciclopedia. Selección, ed. de J. Lough, Madrid, Guadarrama, 1970, pp. 69-94). Isaías Lerner aporta una interesante nota cronológica al respecto: «Los treinta y siete libros que han sobrevivido hasta nuestros días estructuran los variados tópicos de su narración en un ordenamiento a priori que define la $\mathrm{Na}$ turalis Historia como una miscelánea, pero no como una Selva. En efecto, el texto de Plinio se nos presenta como una gigantesca descripción ordenada del mundo y, a su vez, como una recopilación del mayor anecdotario posible a través de todas las fuentes anteriores o contemporáneas posibles. [...] El riguroso orden temático que caracteriza el texto de Plinio, sólo parcialmente interrumpido por al anecdotario relacionado con el tema, no volverá a aparecer sino en los textos que ya no pertenecen al género de la miscelánea sino a los de carácter científico. En cambio, el placer por la acumulación de noticias de todo género para dar riqueza narrativa a la descripción, se va a repetir en las misceláneas posteriores mientras que su desaparición marca la característica fundamental que distingue la prosa informativa del discurso científico» (1998: 72-73).

${ }^{16}$ Las más recientes traducciones al español corresponden a Amparo Gaos Schmidt para la «Bibliotheca Scriptorum Graecorum et Romanorum Mexicana» (México, UNAM, 2000-2006), y a Manuel-Antonio Marcos Casquero y Avelino Domínguez García (Universidad de León, 2006).

${ }^{17}$ Ya había ofrecido Plinio un listado parecido más breve, aunque con sentido peyorativo, en el prefacio de su Historia Natural (1998: 16), obra que figura, por cierto, en la relación de Gelio. 
resulta inevitable poner mientes en el Mejía preocupado por «el público provecho», que ofrece sus «vigilias a los que no entienden los libros latinos», que «son los más y los que más necesidad y deseo suelen tener de saber estas cosas» (MEJÍA, 2003: 40-41), sector que precisaba de la paciente y laboriosa siembra del escritor, y que recoge el fruto rápidamente, como el ocupadísimo destinatario de Aulo Gelio.

Tan importante es este rasgo para caracterizar el género, que de su abuso entre nuestros escritores áureos no faltaron enconadas burlas, como la muy conocida gongorina, que en una hilarante descripción de sus Romances alude, desvirtuando las metáforas vegetales de los dos paradigmas del género, a las misceláneas de Mejía y Torquemada:

Es de tal humor,
que en salud se cría
muy sano, aunque no
de los de Castilla;
es mancebo rico
desde las mantillas,
pues tiene (demás
de una sacristía)
barcos en la sierra,
y en el río viñas,
molinos de aceite
que hacen harina;
un jardín de flores
y una muy gran silva
de varia lección,
adonde se crían
árboles que llevan
después de vendimias
a poder de estiércol
pasas de lejía

(GÓNGORA, 1982: 187) ${ }^{18}$.

Con la mención del cordobés de los dos textos más célebres de nuestra miscelánea renacentista, ingresamos ya en el propósito central de este trabajo, algunos deslindes del género en el panorama complejo de la literatura con apariencia miscelánea de nuestro siglo XVI.

Si a la malicia de Góngora se pueden sumar las alusiones al desorden de estos textos como una anomalía estructural ${ }^{19}$, la recepción del género presenta inmediatamente, tras

\footnotetext{
${ }^{18}$ Recuérdese asimismo La Culta Latiniparla de Quevedo: «Tenga achaques de varias lecciones, y si estuviere preñada, se le antojen Escalígeros crudos» (cito por la reproducción digital de la Biblioteca Virtual Miguel de Cervantes a partir de Obras de Francisco de Quevedo Villegas... I, Amberes, Henrico y Cornelio Verdussen, 1699, pp. 470-471).

${ }^{19}$ Protesta en unos espléndidos diálogos Montano: «habeisnos vos metido en tantas variedades de conversación, que casi paresce nuestra plática una Silva de varia lección o un Jardín de flores» (BARAHONA DE SOTO, 2002: 39-40). Sobre esta mención, $c f$. la explicación de Lara Garrido en «Los Diálogos de la montería de Barahona de Soto: desestructuración expositiva y coherencia compendial», Boletín de la Biblioteca de Menéndez Pelayo, LVIII, 1982, pp. 115-153, en especial pp. 117-118.
} 
la publicación del texto fundacional de Mejía, signos más que positivos. Porque si el empleo indiscriminado y falaz de los repertorios será denunciado, como veremos a propósito de las polianteas, la mínima personalización de la materia en la miscelánea incita también, más allá del mimetismo, a la superación y afán crítico, como ha explicado Asunción Rallo a propósito de la competencia surgida entre Torquemada y el sevillano ${ }^{20}$.

A la Silva se había referido Gonzalo Fernández de Oviedo en múltiples ocasiones, en los que probablemente sean los primeros testimonios sustanciales sobre la obra. En su Historia General y Natural de las Indias, Oviedo suele mencionar al sevillano -siempre acompañándolo de elogios- como catalizador de sus propios comentarios:

En el capítulo XXXII hice memoria de aquel nuevo tractado que un caballero docto ha escripto, llamado Silva de varia leción, y en la verdad, a mi gusto es una de las que más contentamiento me han dado de las que he visto en nuestra lengua castellana. Y entre las otras gentilezas y admirables casos que han pasado, hace memoria del nadar de un hombre, de donde le paresce que tuvo origen la fábula del peje Nicolao; e trae a consecuencia algunas historias de grandes nadadores, y en especial de un hombre llamado el pece Colan, natural de la cibdad de Catania, en Secilia, e de otros, como lo podrés ver, letor, en el tratado que he dicho. Y esto ha seído causa para acordarme de poner aquí un depósito [...] (FERNÁNDEZ DE OVIEDO, 1959: 197)²1;

pero la convivencia in situ con lo que en Mejía es «lección», le lleva a creer que supera lo que el sevillano había contado en su libro:

A mi parescer, todo lo que aquel caballero Pedro Mexía escribe en su Silva de varia leción, de aquellos grandes nadadores que allí pone, todo es poco en comparación de lo que agora diré; porque de nadar un hombre por su placer o por nescesidad, hay mucha diferencia a llevarlo atado e arrastrando debajo del agua por la fuerza de un grandísimo animal marítimo, que los tales son de tanta velocidad, que ningún ligero caballo o ciervo en la tierra no es tan suelto ni ligero. Visto yo he muchas veces [...] (FERNÁNDEZ DE OVIEDO, 1959: 197).

Asimismo práctica saludable, porque representa un empleo crítico y honesto de la miscelánea, es su uso orientador hacia las fuentes primarias, de manera que su condición

${ }^{20}$ RALLO GRUSS, Asunción, «Maravilla y erudición en el Humanismo español: el Jardín de flores curiosas de Antonio de Torquemada», J. Matas y J. M. Trabado (eds.), La maravilla escrita. Antonio de Torquemada y el Siglo de Oro», Universidad de León, 2005, pp. 111-173. Téngase en cuenta que en el Jardín opera a menudo una dinámica dialogal competitiva, donde se interviene en función del «más difícil todavía» (cf. mi Aprendices, escépticos y curiosos en el Renacimiento español. Los diálogos de Antonio de Torquemada, Universidad de Málaga, 2004, pp. 296-298).

${ }^{21}$ En el capítulo XXXII del Libro Sexto al que hace referencia, había citado a Mejía a propósito de su elección terminológica para el «Libro de los depósitos», equiparación interesante por vincular la idea de depósito del saber que va incrementándose sucesivamente con la de una silva que también cobra mayor espesura a medida que va pasando por la imprenta (p. 190). La jugosa recepción de la Silva por parte de Oviedo requeriría trabajo monográfico. Nótese, por ejemplo, cómo le sirve la miscelánea del sevillano a modo de impulsor temático, con referencia explícita a su apoyo mnemotécnico: «Leyendo esta Silva de varia leción que escribió el noble [y] muy enseñado caballero Pedro Mexía [...], despertador de trabajos míos (que aunque algunos son pasados, no pueden salir de mi memoria en tanto que el ánima estoviere en esta mi flaca e pecadora persona), y estos se recentaron cuando leí el capítulo XXVIII de su tractado», donde halló anécdota que él ya había leído en su caro Plinio (p. 198). Algo ha apuntado sobre esta relación Isaías Lerner en «La visión humanística de América: Gonzalo Fernández de Oviedo», en Ignacio Arellano (dir.), Las Indias (América) en la literatura del Siglo de Oro: homenaje a Jesús Cañedo, Kassel, Reichenberger, 1992, pp. 3-22. 
de intermediario sale a flote, circunstancia que ya operaba de hecho en la propia Silva, miscelánea que aprovecha otras misceláneas. Oviedo toma como punto de referencia, nuevamente, a Mejía, pero insiste en que ha consultado directamente las autoridades alegadas por el sevillano:

Un caballero llamado Pedro Mexía, natural de la cibdad de Sevilla, de noble progenie y varón docto (que al presente vive), en un su tractado intitulado Silva de varia leción, pone un capítulo y es el XXV de la primera parte, y dice cómo al principio del mundo todos los hombres hablaban una lengua, y cuál lengua fué ésta, e por qué vino la confusión de las lenguas, e qué tal e dónde fué la torre de Babilonia; e que si dos niños se criasen, sin les hablar nada, cuál lengua se cree que hablarían. Y de todo lo que es dicho, da suficientes y verdaderas razones y aprobadas auctoridades, con la Sagrada Escriptura e otros autores graves y auténticos, en lo que dice. Bien he visto yo lo que en esta materia se tracta en el Génesis que él alega, y asimismo lo que el Isidoro en sus Ethimologías nos acuerda, donde dice: «Linguarum diversitas exorta est in ædificatione turris, post diluvium» (FERNÁNDEZ DE OVIEDO, 1959: 202).

Aunque la utilización por parte del escritor de estos textos misceláneos, como de cualquier obra literaria, dependa en última instancia de su responsabilidad y honestidad, es el corpus afín de las polianteas y repertorios de lugares comunes -y aquí proponemos nuestro primer deslinde- el que estaba llamado al abuso y consiguiente denuncia. El hecho de que la operación fundamental en la composición de una poliantea sea la copia y relación alfabética de segmentos de erudición descontextualizada, sin que medie excesivamente la selección y ordenación intelectual del escritor, era ya sospechoso de entrada, porque invitaba al mecanicismo de la cita y, sobre todo, si atendemos al juego terminológico de Víctor Infantes con el término «secreto» que asocia a estos libros, porque apuntaba al oscurecimiento de las fuentes:

[...] estas polyantheas circularon, se consultaban, se compraban y se ocultaba (habitualmente) la cita de su conocimiento; de ahí lo secreto del título, esa noción de silenciosa complicidad con el repertorio amigo, de restringida mención, de callado aspaviento. Una cultura que hace gala de la propia cultura como emblema [...] necesita un cómplice discreto que la sustente para que el artificio se dignifique con una fuente segura; es la sabiduría de la apariencia, más ornada cuanto más inasequible resulte su comprobación (INFANTES, 1988: $246-247)^{22}$.

No es de extrañar, pues, que encontremos, junto a menciones de apariencia aséptica, como la de María de Zayas en el preliminar de sus Novelas amorosas y ejemplares ${ }^{23}$, decididas críticas sobre el abuso de esa erudición huera que propiciaban las polianteas. Como no extraña tampoco que sea en el «Siglo de las Luces» cuando salten más las alarmas. Así, por ejemplo, leemos esta prescripción en La derrota de los pedantes de Leandro Fernández de Moratín:

${ }^{22}$ El corpus de estos textos ha sido difundido por Sagrario López Poza en «Florilegios, polyantheas, repertorios de sentencias y lugares comunes. Aproximación bibliográfica», Criticón, 49, 1990, pp. 61-76.

${ }^{23}$ «Y que después que hay Polianteas en latín, y Sumas morales en romance, los seglares y las mujeres pueden ser letrados» (ZAYAS, 2000: 160), palabras que conviene leer en su línea de reivindicación de la escritura femenina, que necesita para su desarrollo un más amplio acceso a la cultura libresca. 
¿Llegará el día en que se aprenda por principios?, ¿en que se estudien los grandes modelos de la antigüedad?, ¿en que sepáis conocer los que dejaron los autores de vuestro siglo de oro?, ¿aquellos que trayendo entre los despojos de las conquistas las ciencias y las artes que hallaron florecientes en la vencida Italia, las cultivaron después en su país, haciendo gloriosa entre las demás por su sabiduría a aquella misma nación que dio leyes al mundo por su política y sus victorias?

Entonces no se instruían los españoles en compendios y polianteas. No era tan universal su literatura, porque era menos pedantesca, menos frívola. Los grandes hombres que ha producido España, entonces los produjo. Las obras de mérito que tiene la nación, entonces se escribieron. Estudiadlas (1973: 79-80).

Y en el Fray Gerundio de José Francisco de Isla, tras indicar el maestro Prudencio al protagonista en qué consiste la verdadera sabiduría, le dice este último:

-Eso sería bueno -replicó fray Gerundio- si los predicadores hubiesen de predicar de repente. Pero en no admitiendo sermones si no es con dos o con tres meses de término, está todo remediado; porque en este tiempo se pueden tomar de las bibliotecas y de las polianteas cuantas especies se quieren de todas las facultades, no sólo para llenar, sino para atestar un discurso.

-Así saldrá él -respondió el maestro Prudencio-, y no habrá hombre entendido que no lo conozca. A las mujeres, al populacho y a aquellos semisabidillos que solamente lo son por lectura de socorro, puede ser que les parezca cosa grande; pero los que tienen buenas narices al punto perciben el fárrago, la inconexión, el hacinamiento y la indigestión de las especies, que ninguno tiene peor sabidas que el mismo que las ostenta con tanto aparato. No hizo más que trasladarlas del libro al papel, del papel a la memoria, de la memoria a los labios; y si se las tocan dos días después, le cogen tan de repente como si jamás las hubiera decorado. Predicadores jornaleros, que sólo trabajan lo que basta para salir del día. Quien no gasta muchos años en prepararse de antemano, nunca se preparará de repente; y al contrario, presto se dispondrá bien para un sermón particular el que anticipadamente se halla ya prevenido para todos (ISLA, 1991: 283-284).

Hay una diferencia fundamental que aconseja distinguir nítidamente entre miscelánea y poliantea. La puede ilustrar una de «las ridículas reglas para predicar» que le ofreció fray Blas a fray Gerundio en la obra del Padre Isla: entre los libros que todo buen predicador ha de tener a mano, la mayoría han de ser polianteas y repertorios, que, como el Florilegio Sacro de Soto Marne, son una auténtica «India»; «para nada son menester» -responde a la inquietud de fray Gerundio- «algún expositor o Santo Padre», pues

cuando quieras apoyar algún concepto o pensamientillo tuyo con autoridad de algún Santo Padre, di que así lo dijo el Águila de los Doctores, así la Boca de Oro, así el Panal de Milán, así el Oráculo de Seleucia. Y pon en boca de San Agustín, de San Juan Crisóstomo, de San Ambrosio o de San Basilio lo que te pareciere; lo primero, porque ninguno ha de ir a cotejar la cita; y lo segundo, porque aunque a los Santos Padres no los [sic] hubiese pasado por el pensamiento decir lo que tú dices, pudo pasarlos [sic] (ISLA, 1991: 311-312).

Los usuarios principales de las polianteas son aquellos que se dirigen al «vulgo», incapaz de verificar la identidad de las citas y la idoneidad de su recurrencia. Predicadores o escritores de ficción, si son indolentes, se amparan en la ignorancia de sus receptores, 
reflejo de la suya propia ${ }^{24}$. En cambio, la miscelánea no está dirigida específicamente al profesional de la oratoria sagrada o de la creación ficcional, sino que surge en el entramado humanístico, en primer lugar, para el lector curioso que, sin posibilidad de escritura, pondrá en práctica sus recientes descubrimientos lectores, en todo caso, en la plática cotidiana, problema de otro orden al que pasaremos enseguida con el diálogo misceláneo; $\mathrm{y}$, en segundo lugar, para ese mismo círculo humanista que parece obrar con mayor responsabilidad en cuanto a su uso de fuentes, máxime cuando una de las señas de identidad de lo que hoy se conoce como humanismo es precisamente la collatio y la pulcritud filológica, que crean la costumbre de mirar con más rigor y atención el caudal textual que se ha descubierto y se va a difundir.

Tal vez el mal uso de estos repertorios, que de ser un útil auxilio de la memoria, vinculado en principio a un saludable ejercicio académico, se convirtió en saber hacinado y farragoso, no sea sino la imagen especular de su mismo proceso de elaboración y apariencia final. Compárese, por ejemplo, el precioso capítulo quinto de la primera parte de la Silva de varia lección, «Cómo está bien alabada y es gracia singular el hablar poco y brevemente; y, por el contrario, los habladores y parleros son aborrecibles: en prueba de lo cual se traen historias y dichos de sabios», con el apartado «De la lengua» que hallamos en los Lugares comunes de conceptos, dichos y sentencias en diversas materias (1594) de Juan de Aranda (1613: 88ํ-91), y se apreciará la distancia que media entre un discurso muy próximo a lo que hoy conocemos como ensayo, y una desangelada relación de sentencias acompañadas exclusivamente de la fuente al margen. Pero ni siquiera en esto último ha sido sistemático el compilador, amparado en su «Prólogo al lector», donde había avisado de que «se procura comprovar qualquier dicho, razón o sentencia, con su autor, muchas de las cuales, y otras de las que no le tienen, son propias; y otras tan naturales y conocidas, que no tienen necessidad de prueva» (ARANDA, 1613: s. n.). La frontera de la cita queda así cómodamente diluida para el autor, y también para el lector, con lo que se acrecienta el peligro ante el que reaccionan Moratín y el Padre Isla.

Lo mismo podría decirse de florilegios, libros de apotegmas y recopilaciones paremiológicas, corpus bien establecidos y caracterizados por la crítica, pero que a menudo se confunden con las misceláneas en el panorama difuso de lo que estamos denominando de modo muy general «literatura en segundo grado ${ }^{25}$. Si en este tipo de listados de anéc-

\footnotetext{
${ }^{24}$ Así queda de manifiesto en otra de las muchas críticas que se hallan en Isla: «Para llenar, no digo yo un sermón, sino cien tomos de a folio de citas, autoridades, testimonios, sentencias, versos, historias, ejemplos, símiles, parábolas, símbolos, emblemas y jeroglíficos, no es menester más que hacinar y recoger. Tanto sentenciario, tanto libro de apotegmas, tanta poliantea, tanto teatro, tanto tesauro, tanto diccionario histórico-crítico-náutico-geográfico, tanta biblioteca, tanto expositor que va discurriendo por los lugares comunes e infarcinando en cada uno todo cuanto se le viene a la mano, en fin, tanta selva de alegorías y de dichos como cada día brota en esas naciones y en esas librerías, hacen erudito de repente al más boto, al más mentecato, al que no sabe quién reinó en España antes de Carlos II. No hay más que abrir, trasladar, embutir, y está hecha la maniobra. Al ver un sermón atestado de esa borra, quedan aturdidos los páparos, entre los cuales cuento a muchísimos que no lo parecen; mientras los verdaderos eruditos, o gimen corridos, o se ríen desengañados, según el humor que los predomina. Más de una vez oí a hombres de gran juicio que se debían desterrar del mundo literario estos almagacenes públicos de erudición tumultuaria; porque sólo servían para mantener haraganes, mientras perecían de hambre los ingenios verdaderamente industriosos» (ISLA, 1991: 571).

${ }^{25}$ Cf. las precisiones de Alberto Blecua en «La littérature apophtegmatique en Espagne», en A. Redondo (ed.), L'Humanisme dans les lettres espagnoles, París, Vrin, 1979, pp. 119-132; y María del Pilar Cuartero en su «Prólogo» a Melchor de Santa Cruz, Floresta española, Barcelona, Crítica, 1997, pp. XXIX-XXXII.
} 
dotas, dichos y sentencias, el compilador se limita a la antología, pero no interviene personalizando de algún modo el material recopilado ${ }^{26}$, cabe considerar, en los límites de la literatura paremiológica, la relación con la miscelánea de un particular modo de compilación, el practicado por Juan de Mal Lara en su Filosofía vulgar. Porque las glosas del humanista sevillano, consideradas independientemente del refrán que las impulsa, cobran mayor relieve que la labor de rescate de la sentencia, ya practicada en forma de listado por muchos otros, entre ellos Hernán Núñez y Pedro Vallés, citados por el propio autor.

El conflicto, a la hora de realizar estos deslindes, con un tipo de glosa como la de su paisano Fernando de Herrera en sus Anotaciones a Garcilaso, se salva si tenemos en cuenta que Herrera opera sobre un texto homogéneo (el corpus poético del poeta toledano, y no el inaprensible mundo de la sabiduría popular) y se dirige a un lector culto, igual que -respecto al segundo rasgo- el Erasmo de los Adagios. Asunción Rallo, que ha insistido en la adscripción al género misceláneo de la Filosofía vulgar, explica la diferencia fundamental respecto a la obra del roterodamo, advirtiendo

un gran abismo respecto al uso que Erasmo pensaba para sus Adagios, tanto en la utilidad lexicológica como en la cultural; si la base era el desentrañamiento de un enigma o sentido oculto, el receptor tenía que ser algo más que mediocre erudito. Para Mal Lara el origen de sus proverbios era popular, su explicación podía también serlo, y su público escapaba de la élite erudita, para, a semejanza de las otras misceláneas españolas, dar entretenimiento y cultura a los curiosos «amigos y vecinos». Mal Lara traslada el doble valor de los adagios (expresión y saber) a los refranes, y los refrenda en su propia sociedad (2003: 84).

Las coincidencias con el propósito y los medios con los que contaba su también paisano Mejía son demasiadas para pasarlas por alto. Si atendemos al prólogo de la obra y a los «Preámbulos de la Vulgar Philosophía sobre todas las partes de los refranes», notamos cómo Mal Lara escribe guiado por esa responsabilidad social que alumbraba al humanista, «aprovechar a todos los de mi patria, y por ellos a los demás, con aquella parte de talento que fue Dios servido de concederme» (1996: 21); invita explícitamente a que el lector, para ahorrar esfuerzo, realice una lectura circunstancial y no de corrido, siguiendo el ejemplo de Plinio, a quien menciona estratégicamente tras la Silva de Pedro Mejía; y, sobre todo, es consciente de que está practicando un tipo de escritura novedosa, circunstancia a la que dedica todo un epígrafe de sus prolegómenos, «De la novedad de glosar refranes», que, llevada a buen puerto, le permite afirmar que «mi intento es bueno, pues tiene más arte, y assí trairá mayor provecho que todos los libros que, hasta aquí, tratan de refranes» (49).

Podemos concluir que de la colección de refranes a la Filosofía vulgar hay un salto cualitativo similar al que ya establecimos entre la descarnada poliantea y la miscelánea. Si toda frontera genérica, cuando el marbete es de acuñación posterior al mismo acto creativo, no es sino el modo de agrupar cómodamente el maremágnum textual de cada

${ }^{26}$ Llama la atención que no gustara entre sus contemporáneos la fórmula de apotegma «personalizado» de Rufo, frente a la más exitosa de Santa Cruz, cuya Floresta resultaba más práctica y orgánica para el lector, en tanto que -apunta Alberto Blecua en la línea del uso que estamos apuntando de la poliantea- «los apotegmas de Rufo son personales y, por lo tanto, inalienables» («Introducción» a Juan Rufo, Apotegmas, Sevilla, Fundación José Manuel Lara, 2006, p. LV). 
época, el término miscelánea rinde más desde un punto de vista descriptivo e interpretativo que el de compilación paremiológica, aplicados ambos a la insólita obra de Mal Lara, en tanto que la glosa o comentario tiene un lugar suficientemente sólido en la historia literaria como para confundir la variedad resultante de la anotación con el género misceláneo. En la exégesis de Herrera, las miras están puestas en el poeta toledano; en la de Mal Lara, el objeto de estudio se difumina en la preciosa escritura miscelánea que nos ofrece.

Nos dejamos en el camino, al citar una posible derivación práctica y cotidiana de la miscelánea, la faz conversante. Ya en la literatura grecolatina, del variadísimo cómputo erudito de un amigo de las «lecciones» nocturnas, Aulo Gelio, a la representación de su puesta en práctica durante la diurna vida social, podíamos dar un salto al género no sólo dialogal, sino también convival, y toparnos con dos de los referentes evocados por Mejía: Macrobio y sus Saturnales, Ateneo y su Banquete de los eruditos. Si la Silva de varia lección, fiel depositaria de la misión social que se proponía su autor, se vinculó «al valor ciudadano de alternancia y mezcla de argumentos propia del humanista, capaz de hablar de muy diversos temas con muy distintas personas en oposición a la incomunicación del especialista orientado en una sola dirección», y «se extendió así tanto para servir al comportamiento ciudadano como para generar o estimular nuevas obras que prosiguieran su surco o que buscaran otras formas» (PRIETO, 1986: 220, 221), resulta lógico que el permeable género dialogal, como memoria literaria que es -en sus mejores frutos- de esa ebullición conversacional de la vida ciudadana, recogiera el espíritu que anima a la miscelánea. Claro que aquí, como en el brevísimo recorrido que hicimos por los antecedentes clásicos del género, hay que obrar con suma cautela.

Un criterio para establecer deslindes es el cualitativo, en oposición a la engañosa acumulación cuantitativa. Y la cantidad, que genera fortuitamente variedad, se manifiesta de dos formas que han dado lugar a error.

Por una parte, la confluencia de varios diálogos independientes, reunidos y publicados bajo un mismo título, aunque se compusieran ex profeso para la edición conjunta, no implica en absoluto que estemos ante diálogos de tipo misceláneo. Los Coloquios satíricos de Antonio de Torquemada, que Manuel Fernández Nieto ${ }^{27}$ incluye entre las misceláneas, no lo son en modo alguno ${ }^{28}$, pero sí su Jardín de flores curiosas, como ha venido a establecerse desde que Asunción Rallo lo propuso y justificó en el artículo más celebrado sobre el género (1984: 172-175).

Por otra parte, sorteada la dificultad que ocasiona la yuxtaposición de varios diálogos independientes, hay que tasar, en el caso de los diálogos de estructuración unitaria, si la disgregación temática es signo inequívoco de intención miscelánea. Así, aunque «la serie de digresiones y la desmesura de algunas enumeraciones conduce a un rasgo particular del Diálogo en laude de las mujeres: la ruptura del marco dialógico por el sistema

${ }^{27}$ FERNÁNDEZ NIETO, Manuel, «Función de los géneros dramáticos en novelas y misceláneas», en Criticón, 30, 1985, pp. 151-168. Llama la atención que Fernández Nieto, equiparando los Coloquios satíricos a la Selva de aventuras de Jerónimo de Contreras, los considere una miscelánea, en tanto que alude a su Jardín de flores curiosas sólo a pie de página y para indicar que «también es muy interesante Jardín de flores [...]; fue obra muy conocida en su tiempo y pudo ser base para alguno de estos libros híbridos entre teatro y novela» (p. 153).

${ }^{28}$ Cf. el cap. 2 de mi citado trabajo Aprendices, escépticos y curiosos..., en especial p. 174, donde se aprecian por medio de un cuadro comparativo los matices diferenciales de los seis primeros coloquios, que impiden asignar al conjunto etiqueta alguna, y menos la de miscelánea. 
desintegrante y acumulativo propio de la miscelánea» (RALLO GRUSS, 1987: 98), esta obra de Juan de Espinosa parece no tanto un diálogo misceláneo, sino un diálogo polémico deficientemente construido. La incorporación de variados materiales librescos al discurso de Philalithes y Philodoxo, cuyos nombres parlantes ('amigo de verdad', 'amigo de opinión') no dejan lugar a dudas sobre quién saldrá victorioso en la contienda, no constituye un fin por sí sola; por el contrario, está subordinada a la demostración de que Philodoxo se equivoca al lamentarse de que su mujer, cuando él «sperava con incomparable deseo que huviesse de parir y darme un hijo, parió esta noche passada, por mi mala suerte, una hija. Cosa para mí de mayor dolor y pesar que si ambas en el mismo punto murieran» (ESPINOSA, 1990: 70). Que los procedimientos argumentativos, empleados con singular impericia, lleven anejos gran número de autoridades muy diversas, recogidas independientemente en una tabla, no quiere decir que este texto de índole moralizante se destine a la consulta circunstancial, pues elementos paratextuales como índices, epígrafes marginales y tablas pueden aparecer en cualquier género, incluido el novelístico ${ }^{29}$.

Más útil parece, en busca de una caracterización del diálogo misceláneo, considerar una dinámica dialogal diferente de las otras tres grandes posibilidades en el amplio cultivo del género en nuestro siglo XVI. Si podemos hablar de transferencia de datos con objeto pedagógico en el diálogo catequístico (Diálogo de doctrina cristiana de Juan de Valdés, Manual de escribientes de Antonio de Torquemada, Medidas del romano de Diego de Sagredo, etc.), de contienda en el diálogo polémico (Diálogo de la dignidad del hombre de Fernán Pérez de Oliva, Diálogo de las cosas ocurridas en Roma de Alfonso de Valdés, primero de los Diálogos de Pedro Mejía, Argumento de vida de Juan de Molina, etc.) y de un uso del diálogo como soporte de una o varias narraciones (El Crótalon de Cristóbal de Villalón, el anónimo Viaje de Turquía, etc.), es posible identificar una actitud netamente cooperativa, por más que uno de los interlocutores se erija como el guía o maestro de las pláticas, en obras que sí podemos rotular como diálogos misceláneos: el Jardín de flores curiosas de Antonio de Torquemada o la Agricultura cristiana de Juan de Pineda.

El humanista astorgano, aun reconociendo en el prólogo que «es tan poderosa la Naturaleza y tan varia en sus cosas, y el mundo tan grande, que cada día vienen a nuestra noticia muchas novedades», y apenas si podemos salir, acabadas nuestras vidas, de «la niñez del entendimiento» (TORQUEMADA, 1982: 96), confía en el intercambio dialogal bastante fluido entre Antonio, Luis y Bernardo, para que al cabo de sus pláticas pueda este último afirmar, al menos, que «lo que habemos dicho es una cifra de lo que queda por decir; y con todo esto no ha sido poco lo que nos habemos atrevido a decir de cosas nuevas» (TORQUEMADA, 1982: 500), recopiladas ahora para el lector interesado en aquellos vergeles de lo asombroso. Para ello, los tres dialogantes, aunque admiten el magisterio del homónimo del autor, se sienten con suficiente capacidad para intervenir ac-

\footnotetext{
${ }^{29}$ De hecho no debemos suponer que la conocida burla de Cervantes en el prólogo de la primera parte del Quijote va dirigida a textos como las misceláneas o las polianteas, sino a una exhibición de autoridades en obras de ficción a la que él se sustraía aderezando su libro «sin acotaciones en las márgenes y sin anotaciones en el fin del libro, como veo que están otros libros, aunque sean fabulosos y profanos, tan llenos de sentencias de Aristóteles, de Platón y de toda la caterva de filósofos, que admiran a los leyentes y tienen a sus autores por hombres leídos, eruditos y elocuentes» (CERVANTES, 1996: 17), y no es difícil pensar aquí y pocas líneas más adelante en el Lope de la Arcadia, el Peregrino en su patria o el Isidro.
} 
tivamente, y no sólo como ávidos domandatori, en el transcurso de los seis espléndidos coloquios.

Por su parte, Pineda nos presenta a «algunos amigos que, como familiares y llanos y conversables entre sí, se avienen bien, sin pundonores de cumplimiento ceremonial y que llaman de pelillo, sino que como lo sienten ansí lo dicen, tomándolo todo a buena parte y dicho con buena intención, que son condiciones necesarias en la buena conversación» (PINEDA, 1963-1964: I, 5), de acuerdo con una declaración de intenciones muy próxima a la de Mejía en su Silva. Pineda manifiesta consagrarse al «bien del prójimo»,

y como el bien universal prepondere al de cada particular, quien pudiese hacer bien a muchos y se contentase con pocos no se guiaría por las reglas de la prudencia ni le movería la más perfecta caridad. Y entendiendo yo esto y que los gustos de los hombres son muy varios también en el manjar del alma, que es la sabiduría y virtud, como en los manjares corporales con que sustentamos los cuerpos, ya que me determiné tomar la pluma para escrevir cosas de provecho, procuré trazarlas de manera que no solamente pudiesen aprovechar a muchos, sino a todos, quien por un respecto, quien por otro (1963-1964: I, 4).

El amplísimo y heterogéneo caudal de conocimientos incorporado en el Jardín y la Agricultura cristiana ya no deriva de anomalías constructivas o de yuxtaponer diversos diálogos, sino de que varios ciudadanos de cultura media, presididos por uno más versado, intervienen alternativamente en función de sus inquietudes. Así, el diseño a modo de preguntas y respuestas de la modalidad catequística, o la controversia -a menudo resultante de la suma de extensos discursos- de la polémica, quedan superadas por la más estricta cooperación del diálogo funcionalmente misceláneo, donde, como indica Filaletes en los coloquios de Pineda, es necesario que «quien sacare la liebre la mate, porque no es razón que cargue todo el trabajo sobre uno» (1963-1964: III, 63).

Queda por revisar una de las propuestas iniciales de este trabajo, donde mencionábamos posibles manifestaciones actuales de la miscelánea. ¿Existen hoy día recopilaciones semejantes de saber heterogéneo para el lector curioso? Lo que conocemos como mass media ha acrecentado el espectro divulgativo y, sobre todo, ha acelerado el acceso a la información, multiplicando así las dos vertientes fundamentales de la miscelánea renacentista: a) su cualidad de atajo; b) para un receptor nuevo, producto de la Imprenta. Con el amplio alcance del periodismo, ya sea radiofónico, televisivo o por el cauce de la prensa escrita, a los que hemos de sumar Internet, parece que se colma con creces aquella curiosidad que evocaba Torquemada como eje incitador en su Jardín. Ciñéndonos a la esfera bibliográfica, es posible encontrar al frente de obras afines, que inciden en lo insólito, declaraciones muy similares a la del astorgano, como estas en el breve prólogo de un libro sin autor expreso:

Alguien dijo en una ocasión que el afán de saber es infinito, tanto como lo es el concepto en sí mismo. Por mucho que nos afanemos, nunca podremos llegar a saberlo todo, pues sólo la idea de intentarlo impone una inevitable sensación de vértigo. Son tantas y tantas las incógnitas por descubrir para cada uno de nosotros, que una vida entera no bastaría para dar solución a todas. Nuestra intención es reducir una modesta parte de ellas. Con tal objetivo este libro presenta una esmerada recopilación de respuestas a preguntas y cuestiones increíbles a veces, e inusuales otras, pero que a más de un lector, sin duda, le dejarán boquiabierto. Se trata de una exten- 
sa variedad de planteamientos acerca de los más diversos temas: cómo es el mundo que nos rodea, el Universo, la Tierra, los seres vivos, las proezas humanas, etc., en definitiva, saberes que a todos nos gustaría incorporar a nuestro finito conocimiento (Increíble pero cierto, 2000: 9).

Contrasta el estilo aséptico y desangelado de un libro anónimo que, a tenor de sus ilustraciones y de su editorial, parece destinado a público juvenil, con las cualidades de otros más cuidados por sus responsables, como este de mayor calidad, en cuyo prólogo se vuelve a insistir en los rasgos de la miscelánea que hemos rastreado:

Sentir curiosidad es señal de buena salud. El curioso tiene buena cara, come bien y come de todo, y eso se le nota. En este libro no ha entrado de todo, por supuesto, ni siquiera todo lo que yo hubiera querido, pero da para una lectura introductoria al mundo de los hechos singulares, insólitos, curiosos, sorprendentes o como quiera llamárseles, que una gavilla de sorpresas sí que esconde y el resultado, aunque humilde, puede redundar en lectura ágil, amena, heterodoxa y curiosísima. [...] La bibliografía sobre estos temas ya va siendo abundante. El número de curiosidades que cualquier compilador podría reunir es inmensa, y siempre fruto de muchas y muy variadas lecturas. Por tanto la selección es obligatoria, lo que imprime un carácter antológico inevitable a la obra. Quiero decir con esto que al final lo que hacemos todos los que hemos recopilado alguna serie de hechos singulares es reunir aquéllos que a nosotros nos han llamado la atención, y narrarlos una vez más a nuestra manera, aunque antes hayan sido contados por otros muchos, que esto no puede evitarse. Quienes en estos derroteros pretendan ser originales llevan el camino un poco equivocado (CELIS SÁNCHEZ, 2001: 9-10).

Si la literatura apotegmática ha dejado descendencia como el Diccionario del ingenio de Mauricio Wiesenthal, y no es difícil apreciar la estela de Polidoro Virgilio en la Historia de las cosas de Pancracio Celdrán, podemos encontrar en las librerías volúmenes misceláneos como el Libro Guinness de los Records, algunas compilaciones de Néstor Luján, Gregorio Doval y Carlos Fisas, o los dos cuyos prólogos hemos citado por su semejanza con el desiderátum de Mejía y Torquemada. Si en este tipo de textos se ha aligerado -o incluso eliminado- el recurso de la auctoritas, que hoy se juzgaría un lastre, también se ha perdido un notable carácter ensayístico y un vigor narrativo que no por casualidad puso a la miscelánea en la órbita de los orígenes de la novela para Marcelino Menéndez Pelayo ${ }^{30}$.

Y es que los mejores frutos de nuestra miscelánea en el siglo XVI resultan ser libros únicos e irrepetibles. Para determinar el corpus bibliográfico de la miscelánea renacentista, es preciso, por un lado, ampliar las miras -siempre con cuidado- hacia horizontes textuales como el de la epístola, los libros de preguntas y respuestas o los libros de antigüedades $^{31}$, y, por otro -completando un doble movimiento de tensión y distensión al

\footnotetext{
${ }^{30}$ Compárese, por ejemplo, la frecuente alusión a las relaciones entre humanos y animales en estos textos misceláneos modernos con los relatos, plenos de ternura y gracejo, que ofrecen Torquemada sobre el perro Melchorico del Conde de Benavente (1982: 346), y Zapata a propósito «De un león del señor Don Juan de Austria» (1949: I, 171-172), o el apartado que dedica a los nacimientos múltiples el Libro Guinness de los Records. 1992 (Madrid, Jordán, 1991, pp. 74-75) con las hilarantes rememoraciones de Torquemada en el Tratado Primero de su Jardín (1982: 111-114).

${ }^{31}$ Propuesta esta última que deparará muchas sorpresas atendiendo a la relación que ofrece Asunción Rallo Gruss en Los libros de Antigüedades en el Siglo de Oro, Universidad de Málaga, 2002. El más que necesario establecimiento del corpus ha de efectuarse teniendo en cuenta los apuntes bibliográficos de Isaías Lerner (1998: 78); y las cautelas de Lina Rodríguez Cacho en «La selección de lo curioso en 'silvas' y ‘jardines': notas para la trayectoria del género», Criticón, 58, 1993, pp. 155-168.
} 
examinar determinados rasgos, como la voluntad de desorden-, cerrar el tamiz a manifestaciones bien descritas en otros campos, con salvedades significativas como la de Mal Lara en el ámbito de la paremiología.

No hay autor que pudiera seguir la impronta de la Silva de Mejía, diálogo tan logrado -con tan difícil meta- como el Jardín de Torquemada o escritura tan desconcertante como la de Zapata en su Varia historia. Las mejores misceláneas se definen por sus particularidades. Y no porque sea el término moderno miscelánea un cajón de sastre donde guardar todo aquello que no sabemos definir o clasificar, sino porque la demanda del hombre curioso en sentido más extenso que nunca, hasta entonces, en la historia de la cultura, se produce en una encrucijada de erudición y divulgación donde el ensayo moderno ya se estaba gestando, y el parto dio criaturas singulares al principio. Pero esta del ensayo es otra historia, a la que habremos de dedicar otros desvelos.

\section{REFERENCIAS BIBLIOGRÁFICAS}

AlbReCHT, Michael von (1994): Storia della letteratura latina. De Livio Andronico a Boezio. II, Turín, Einaudi.

ARANDA, Juan de (1613): Lugares comunes de conceptos, dichos y sentencias en diversas materias, Madrid, Juan de la Cuesta.

Bataillon, Marcel (1966): Erasmo y España, Méjico, FCE.

Bustos, José J. de (coord.) (1985): Diccionario de literatura universal, Madrid, Anaya.

BARAHONA DE SOTO, Luis (2002): Diálogos de la montería (estudio preliminar de José Lara Garrido), Archidona, ADR/NORORMA.

Celis SÁnchez, Agustín (2001), Libro de oro de historias curiosas, Madrid, Añil.

Cervantes, Miguel de (1996): Don Quijote de la Mancha. I (ed. de Florencio Sevilla y Antonio Rey), Madrid, Alianza/Centro de Estudios Cervantinos.

Eliano, Claudio (1984): Historia de los animales. I (ed. y trad. de José María Díaz-Regañón), Madrid, Gredos.

EsPinosa, Juan de (1990): Diálogo en laude las mugeres (ed. de José López Romero), Granada, Ubago.

FARRINGTON, Benjamin (1992): Ciencia y filosofía en la Antigüedad, Barcelona, Ariel.

FERNÁNDEZ DE MoRATín, Leandro (1973): La derrota de los pedantes. Lección poética (ed. de John Dowling), Barcelona, Labor.

FERNÁNDEZ DE OviEDO, Gonzalo (1959), Historia General y Natural de las Indias. I (ed. de Juan Pérez de Tudela), Madrid, Atlas.

Gelio, Aulo (1967): Les nuits attiques. I (ed. bilingüe y trad. de René Marache), París, Les Belles Lettres.

BLEIBERG, Germán y MARÍAs, Julián (dirs.) (1964): Diccionario de literatura española, Madrid, Revista de Occidente.

Gómez Pallarés, Joan (2003): Stvdiosa Roma. Los géneros literarios en la cultura romana. Notas para su explicación, de Apio Claudio a Isidoro, Bellaterra, Universidad de Barcelona.

GóngORA, Luis de (1982): Romances (ed. de Antonio Carreño), Madrid, Cátedra.

Increíble pero cierto. 1.000 hechos insólitos (2000), Madrid, Susaeta.

INFANTES, Víctor (1988): «De officinas y polyantheas: los diccionarios secretos del Siglo de Oro», en AA.VV., Homenaje a Eugenio Asensio, Madrid, Gredos, pp. 243-257.

IsLA, José Francisco de (1991): Historia del famoso predicador fray Gerundio de Campazas, alias Zotes (ed. de Joaquín Álvarez Barrientos), Barcelona, Planeta. 
LERNER, Isaías (1998): «Misceláneas y polianteas del Siglo de Oro español», en Juan Matas et al. (coords.), Actas del Congreso Internacional sobre Humanismo y Renacimiento. II, Universidad de León, pp. 71-82.

Mal LaRA, Juan de (1996), Obras Completas, I. Philosophía vulgar (ed. de Manuel Bernal Rodríguez), Madrid, Turner.

Mandosio, Jean-Marc (2003): «La miscellanée: histoire d'un genre», en Dominique de Courcelles (ed.), Ouvrages miscellanées et théories de la conaissance à la Renaissance, París, École des Chartes, pp. 7-36.

MARTIN, René, y GAILlARD, Jacques (1995): Les genres littéraires à Rome, París, Nathan/SCODEL.

MeJ́A, Pedro (2003): Silva de varia lección (ed. de Isaías Lerner), Madrid, Castalia.

PINEDA, Juan de (1963-1964), Diálogos familiares de la Agricultura cristiana (ed. de Juan Meseguer), Madrid, Atlas.

Plinio Segundo, Cayo (1998): Historia Natural (trad. de Francisco Hernández y Jerónimo de Huerta), Madrid, Visor/UNAM.

Prieto, Antonio (1986): La prosa española del siglo XVI, Madrid, Cátedra.

RALlo Gruss, Asunción (1984): «Las misceláneas: conformación y desarrollo de un género renacentista», Edad de Oro, III, pp. 159-180.

—, (1987): La prosa didáctica en el siglo XVI, Madrid, Taurus.

—, (2003): Erasmo y la prosa renacentista española, Madrid, Laberinto.

REYes, Alfonso (1948): De un autor censurado en el «Quijote». Antonio de Torquemada, Méjico, Cultura.

TORQuEMADA, Antonio de (1982): Jardín de flores curiosas (ed. de Giovanni Allegra), Madrid, Castalia.

ZaPATA, Luis de (1949), Varia historia. I (ed. de Isidoro Montiel), Madrid, Castilla.

ZAYAS, María de (2000): Novelas amorosas y ejemplares (ed. de Julián Olivares), Madrid, Cátedra. 